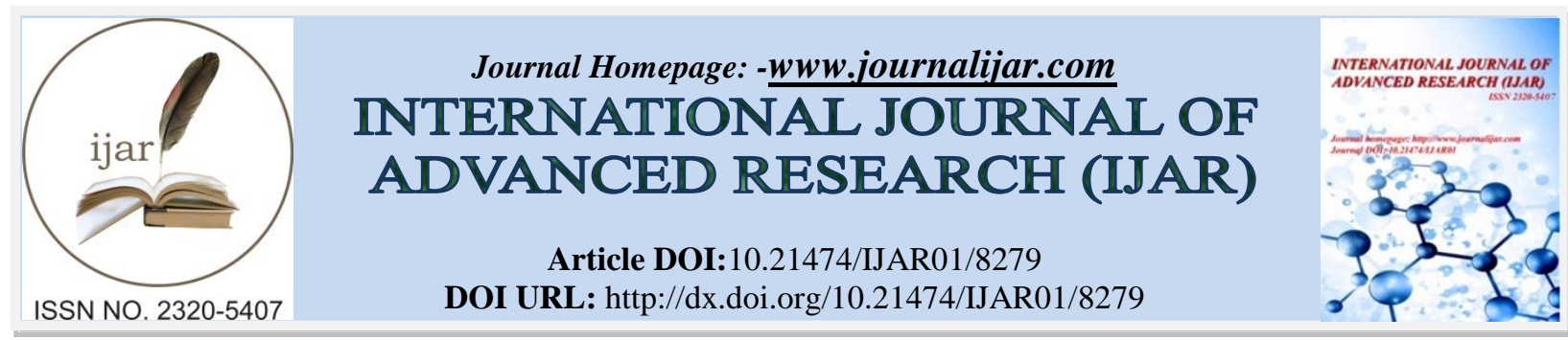

RESEARCH ARTICLE

\title{
SEMI-SAGITTAL SPLITOSTEOTOMY OF ANKYLOSINGBONY MASS FOR RELEASE OF LONG STANDINGAND RECURRENT TEMPOROMANDIBULAR JOINT BONY ANKYLOSIS.
}

\author{
Mohammad Dehis ${ }^{1}$ and Abeer Kamal ${ }^{2}$. \\ 1. Prof. of Oral and Maxillofacial Surgery, Faculty of Dentistry, Cairo University, Cairo, Egypt. \\ 2. Associate Prof. of Oral and Maxillofacial Surgery, College of Oral \& Dental Surgery, Misr University for \\ Science \& technology, Giza, Egypt.
}

\section{Manuscript Info}

\section{Manuscript History}

Received: 20 October 2018

Final Accepted: 22 November 2018

Published: December 2018

\section{Key words:-}

Temporomandibular joint bony ankylosis, Gap arthroplasty,major blood vessels related to ankylosis.

\begin{abstract}
Background:-Gap arthroplasty is a one of the techniques used to release TMJ bony ankylosis with reported many advantages and disadvantages. The aim of this study was to present and evaluate newsemi-sagittal split osteotomy of ankylosing bony massto release temporomandibular joint bonyankylosis. It was intended to minimize the disadvantage of gap arthroplasty.

Patient and methods:-Twelve patients suffering from TMJ bony ankylosis were included in the present study. New semi-sagittal split osteotomy of ankylosing bony mass was implemented. This cut was extended from the most superior point of ankylosing bone mass laterally and directed downward and medially towards the most inferior point of the most constricted part just above the mandibular foramen.Pterygomasseteric sling release was performed.Six quantitative and qualitative calipers were used to assess the technique.

Results:-Postoperative interincisal opening was increased significantly and the lower jaw displaced downward without shortening of the mandibular ramus.Only one case out of twelve $(8.3 \%)$ represented postoperative anterior open bite.

Conclusion:-Semi-sagittal split osteotomy of ankylosing bony mass was recommended to preserve the major vital structures at the base of the skull in long standing and recurrent temporomandibular joint bony ankylosis especially with bulbous bony mass.
\end{abstract}

Copy Right, IJAR, 2017,. All rights reserved.

\section{Introduction:-}

The main principles of management of temporomandibular joint bony ankylosis consists of, resection of the ankylosedbony mass, and early, aggressive and tenacious postoperative physiotherapy to prevent reankylosis.Gap,interpositional arthroplasty, and total joint reconstruction (TJR) either autogenous or alloplastic replacement have been proposed for management of TMJ ankylosis.

Gap arthroplasty is a one of the famous technique used to release TMJ bony ankylosis. It is a procedure of resecting a segment of bone between the base of the skull and the site of existence of mandibular foramen. Two parallel full thickness cut lines usuallycreated from the depth of sigmoid notch and carried downward at $45^{\circ}$ angle to the

Corresponding Author:-Mohammad Dehis.

Address:-Prof. of Oral and Maxillofacial Surgery, Faculty of Dentistry, Cairo University, Cairo, 1373 Egypt. 
posterior border of the ascending ramus. The segment of bone between these two lines is removed to create the gap,it should be as wide as possible to prevent the recurrence. The created gap, should be established at the most superior part of the ramus to maintain maximum ramal height, minimize the possibility of occurrence of anterior open bite and increase the chance of normality of postoperative mandibular functions. ${ }^{(6-8)}$

The advantages of gap arthroplasty are its simplicity, low coast and short operative time. The disadvantages include: creation of psudoarticulation and short ramus, failure to remove all bony pathology, increased risk of reankylosis, extending post-operative follow up and increased possibility of anterior open bite in bilateral cases ${ }^{(9-13)}$. Occlusal derangement is one of the major disadvantages of gap arthroplasty. It is usually take the form of anterior open bite. The muscle action pulls the proximal portion of the mandible upwards. In unilateral cases premature contact of the affected sideand an open bite on the contralateral side were reported.Complications develop as profuse bleeding occurred during surgery whichmay indicate ligation ofexternal carotid artery. Weakening of the facial nerve was reported in upper branch and this attributed tosurgical trauma. In young children, the removal of large section of bone presents surgical and postoperative difficulties as a large percentage of ascending ramus is destroyed.Complications of gap arthroplasty also included infection, otologic complications, parotid gland injury, cranial fossa perforation, reankylosis, and suboptimal postoperative range of movement. ${ }^{(9,14-16)}$

The aim of the present study was to introduceand evaluate the semi-sagittal split osteotomy of ankylosing bony massin thetreatment ofin cases of recurrent and long standingTMJ bony ankylosis. The obtained results may contribute to minimize the disadvantages of conventional technique of gap arthroplasty and improve its results.

\section{Patients and methods:-}

Twelvepatients suffering from TMJ bony ankylosis were included in the present study. They were selected from those attending outpatient clinics, Oral and Maxillofacial Surgery Department of Faculty of Dentistry, Cairo University, Egypt. A detailed history and systematic clinical examination were carried out after taking consent from patients.Inclusion criteriainvolved the recurrent or long standing TMJ bony ankylosis, and bulbous ankylosing bony mass more than the conventional condyle mediolateral and anteroposterior as indicated by CT scan.Exclusion criteria included: young children, medically compromised patients, all types of fibrous ankylosis, patients with short duration of ankylosis and recent recurrent cases. Computerized tomographic scan (CT) were performed for each patients with axial, coronal, sagittal and 3D reformatted images preoperatively for diagnosis of ankylosis, determination of the size of ankylosing bony mass and the site and angulation of cut. Another CT were performed three months postoperatively. Lateral cephalometry were ordered preoperatively and three months postoperatively for calculation of possibledownward mandibular translation.

\section{Analysis of patient's data:-}

The sample comprised8females and 4males with mean of age equal 19.9 years. The group included 8 cases suffering from bilateralTMJ bony ankylosis and 4 cases unilateral ankylosis only. They were complaining of long standing restricted mouth openingwith mean of durationof ankylosis equal to 13 years. The mean of the maximum inter incisal openingpreoperatively was $3 \mathrm{~mm}$. Diagnosisof TMJ bony ankylosis was established on the basis of thorough clinical examinationand CT scan.Preoperative routine blood investigations for general anesthesiawere performed.

\section{Surgical technique:-}

Hospital admission was carried out aday before surgery. Patients were operated under general anesthesia with fiberoptic nasotracheal intubation. They were draped and disinfected as routine program.Local anesthetic (Mepivacaine $\mathrm{HCl}$ 2\%, Levonordefrin $\mathrm{HCl}$ 1:200000 $1.8 \mathrm{ml}$. Alexandria Co. For Pharmaceuticals \& Chemical Industries. Egypt) was injected subcutaneously in the preauricular area for hemostasis.Gain access was carried out via modified preauricular incision. It was made vertically approximately for $4 \mathrm{~cm}$ length just anterior to the helix of the auricle in the preauricular skin fold. The incision was carried out through the skin and subcutaneous tissue blunt dissection was carried out in close contact following the direction of perichondrium and periosteum of the external auditory meatus. Dissection was carried out in this relatively avascular plane and directed downward, inward and forward below and behind the glenoid lobuleof the parotid gland, the condylar mass was approached from the posterior aspect at the level of the root of zygomatic arch.At this point the periosteum was incised and elevated, so the dissection at this plane was carried out at the subperiosteal level. Further elevation was extended anteriorly to expose the sigmoid notch,also caudal dissection started from the lower border of the zygomatic arch so that the joint region could be exposed.(Figure $1 \mathrm{a} \& \mathrm{~b}$ ) 

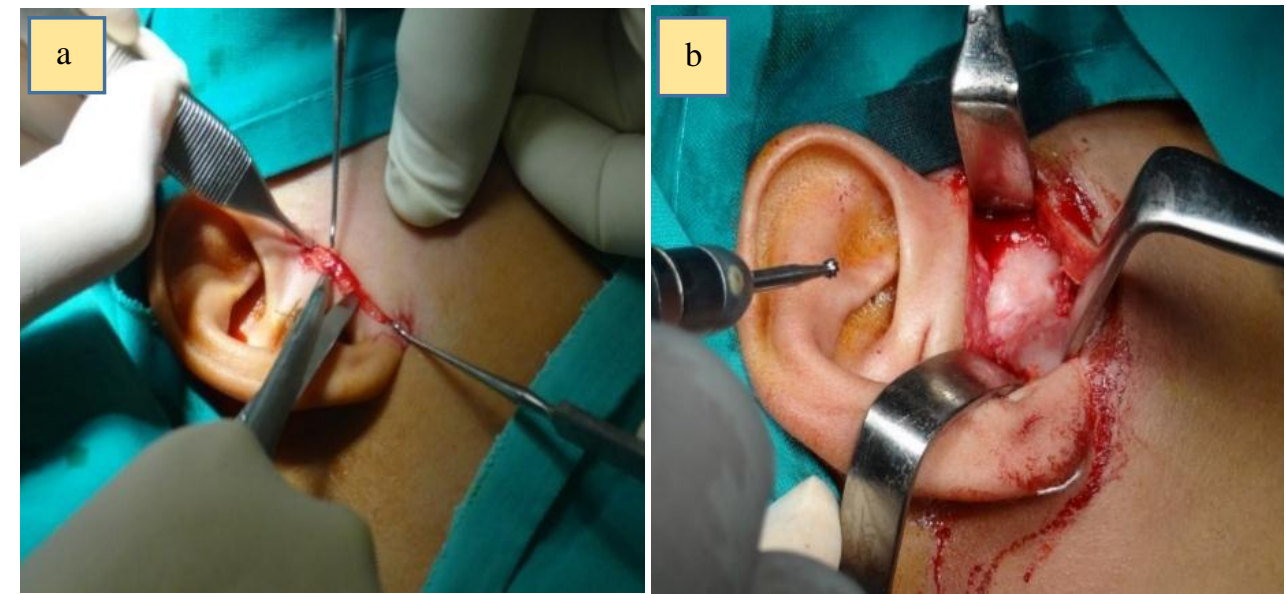

Figure 1:-Surgical steps-a-Incision and sharp dissection.b-Exposed ankylosing bony mass.

The osteotomy cut was performed by drilling multiple horizontal holes using round surgical bur then connected by fissure surgical bur in the outer cortex at most superior point of ankylosing bony mass laterally. The cutthrough the deeper spongy bone was completed by the use of bone osteotome (bibeveled chisel). The angle of inclination of the osteotome was guided by aid ofblade of accessory unibeveled chisel. It was engineered preoperatively with degree of angulation about 130- $150^{\circ}$, this reading wasobtained from interpretation of the CTon coronal cutso it was used only as a guide(Figure $2 \& 3$ ). Delicate knocking by mallet on the cutting osteotome was continued.The cut was gliding by the guide of the unibeveled chisel and directed downwards and mediallytowards the most inferior point of the most constricted part just below the ankylosing bony mass and above the mandibular foramen. The separation was completed finally at the inner cortex by leverage and torque actions using osteotome to induce crack separation of inner cortex of bone. (Figure $4 \& 5$ ).

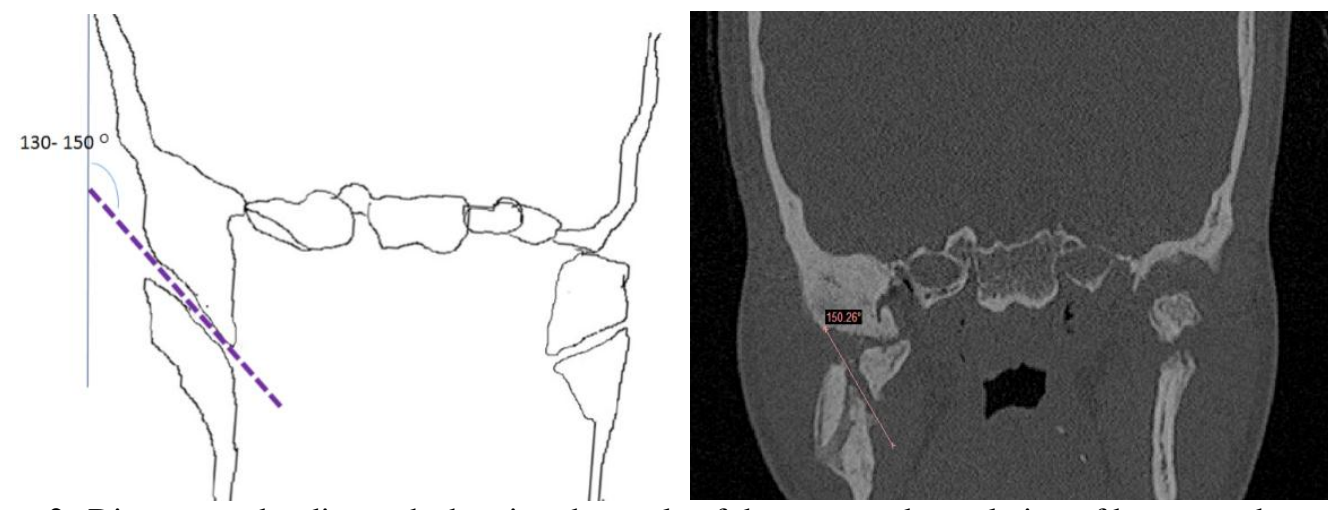

Figure 2:-Diagram and radiograph showing the angle of the proposed angulation of bone cut about (130150.

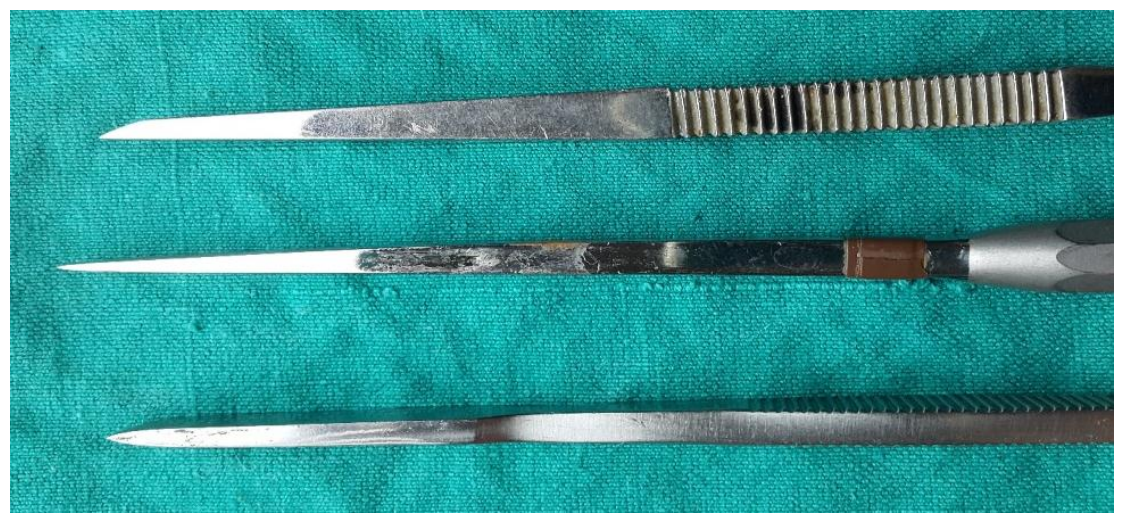

Figure 3:-The usedosteotomes in the present study 
The cut of ankylosing bony mass in this study were obtained at three steps, the outer horizontal cut of the mass by the use of surgical burs, the inner spongy bony is cut by incrementally increased osteotome thickness guided with special pre-determined inclination,and finally the inner cortex was splitted by leverage and torque action of the osteotome at the depth of the previous cut. (Figure 4\&5)

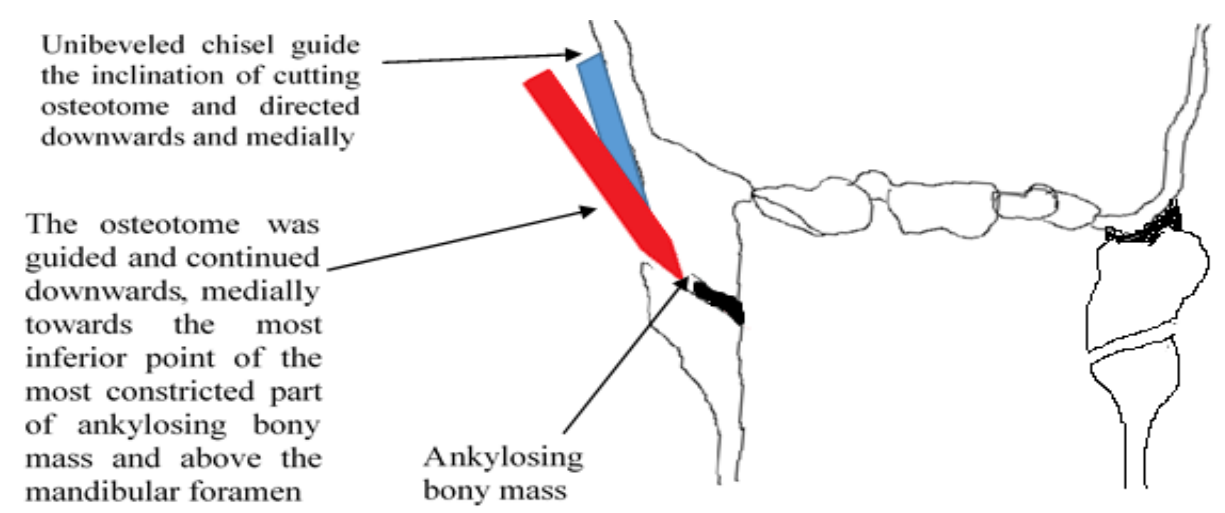

Figure 4:-Diagram showing the angle of inclination of the osteotome was guided by the blade of unibeveled chisel with direction of the cut medially and downward

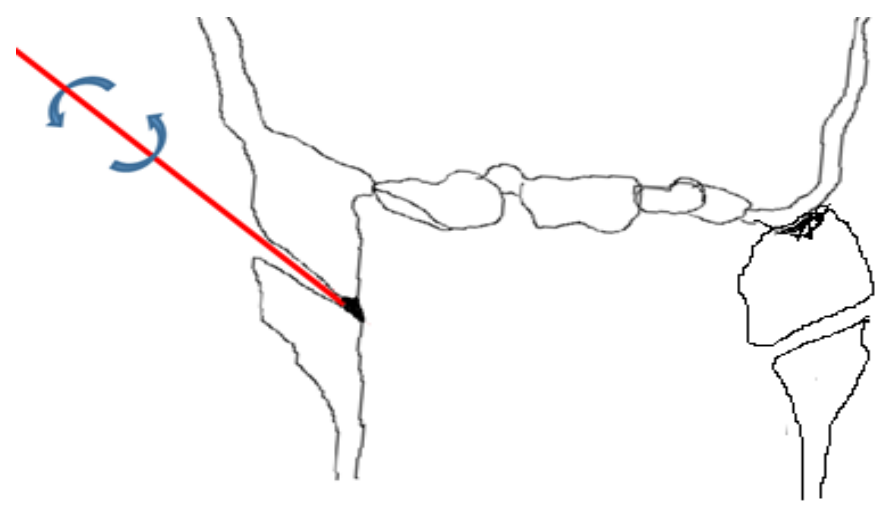

Figure 5:-Diagram showing the inner cortex was splitted by manual leverage and torque action of the osteotome at the depth of the previous cut.

After releasing of ankylosis, the free mobility of the mandible was gained by the use of mouth gag and maximum interincisal opening was recorded at this moment. Pterygomasseteric sling release was performed to achieve free intraoperative satisfactory inter incisal opening (about $35 \mathrm{~mm}$ ). Coronoidotomywere performed if indicated.The semi-sagittal split osteotomy and pterygomasseteric sling release were performed in the other side in bilateral cases (Figure 6-b).

The surgical field was debrided and the remaining bony chips were removed. Copious irrigation with normal saline solution was performed. Vacuum suction drain was inserted subcutaneously via posterior auricular puncture. Closure of the wound were done in layers and finally pressure dressing was applied (Figure 6).
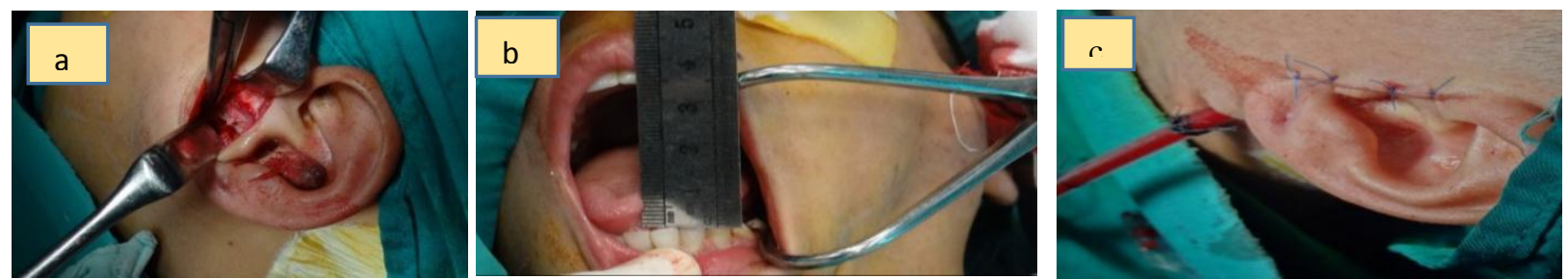

Figure 6:-Surgical steps, a- The created superior lateral cut of semi sagittal osteotomy, b- Intraoperative jaw and obtaining maximum mouth opening, c-Closure of wound and suction drain was inserted 


\section{Postoperative care:-}

It was implemented until discharge of the patients on the second postoperative day. Delayed postoperative care and muscle rehabilitation program were carried out at outpatient clinic to prevent recurrence. The muscle rehabilitation program included negative mouth opening at the first day postoperatively. Forced mouth opening started on the second postoperative day using mouth gag and increasing numbers of intermaxillary wooden tongue blades.Computerized tomograms were performed 3 months postoperativelyfor follow up.

\section{The following quantitative and qualitative calipers were used to assess the technique:-} Intraoperative difficulties:-

1. Hemorrhage.

2. Fragmentation at the osteotomy cut.

3. Need for coronoidotomy.

\section{Postoperative complications:-}

1. Developing of anterior open bite.

2. Interincisal opening.

3. Nerve affection

\section{Tendency for recurrence:-}

Assessment of mandibular translation as a result of semi-sagittal split osteotomy:-

Preoperative and three months postoperativelateral cephalometery were traced.Two points were marked on the tracing of the mandible,B point (the deepest point on the contour of the alveolar process of the mandible) and Go(the most posterior and caudal point on the angle of the mandible). Frankfort horizontal line were also outlined X. The vertical distance between each point in relation to horizontal line (X), represented by line(BX)and (GoX)respectively weremeasured and tabulated.(Figure 7).Comparison were obtained from the pre and three months postoperatively for the detection of any changes due to mandibulartranslation.

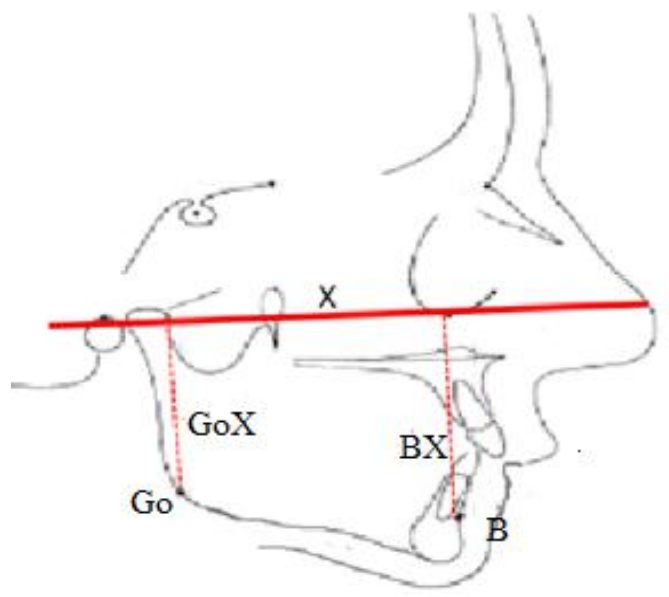

Figure 7:-Mandibular tracing. BX isthe vertical distance between B point and Frankfort horizontal line XwhileGoX is the vertical distance between Go and Frankfort horizontal line $\mathrm{X}$

\section{Statistical analysis:-}

Unpaired T- test for the detection of significance of changes in mandibular position that might be attained postoperatively has been done. Using SPSS test. Version 20 for Windows 2016.P value $\leq 0.05$ was considered statistically significant.

\section{Results:-}

The postoperative course was uneventful. The patients discharged on the second postoperative day with their normal activity and started muscle rehabilitation programin outpatient clinic as following:

1. Every day for the first two weeks.

2. Three times per week for the next two weeks.

3. Twice a week the following month. 
4. Once a week till 6 months.

Intraoperative difficulties:-

Hemorrhage:-

Only one case $(8.3 \%)$ developed intraoperative bleeding that was controlled with pressure pack and applying gel foam for hemostasis with no need for blood transfusion.

\section{Fragmentation at the osteotomy cut:-}

It was seen in only one case $(8.3 \%)$.

Need for coronoidotomy:-

It was carried out in four cases $(33 \%)$ to obtain satisfactory intraoperative interincisal opening.

\section{Postoperative complications:-}

Developing of anterior open bite:-

Only one case out of twelve $(8.3 \%)$ represented immediate postoperative open bite. The case was managed and improved by heavy intermaxillary anterior elastic traction and guided muscle rehabilitation program

\section{Interincisal opening:-}

The mean of the preoperative interincisal opening was $3 \mathrm{~mm}$. There was significant increase in the interincisal opening postoperatively after 3 months with mean equal $36 \mathrm{~mm}$ with p value $(\mathrm{P}<0.0001)$.

\section{Nerve affection:-}

Two cases (16.7\%) showed numbness of lower lip. Three cases showed affection of the zygomatic and frontal branches of facial nerve $(25 \%)$. The problems was resolved after two to three weeks by physiotherapy.

\section{Tendency for recurrence:-}

only one case out of twelve $(8.3 \%)$ showed recurrence of ankylosis.

Assessment of mandibular translation as a result of semi-sagittal split osteotomy:-

on studying the tracing of the mandible on lateral cephalometryit has been observed that the lower jaw displaced downward postoperatively. The B point and Gonion weremoved downward in relation to Frankfort horizontal (X)with mean $6.37 \mathrm{~cm}$ and $2.69 \mathrm{~cm}$. This movement was statistically significant with p-value 0.00001 and 0.021 respectively. (Table1).

Table 1:-T- test for thedownward displacement of the mandible in mm B point and Go in relation to Frankfort Horizontal (X).

\begin{tabular}{|c|c|c|c|c|}
\hline & $\mathrm{BX} *$ pre & BX post & GoX ** pre & GoX post \\
\hline Mean & $7.45+0.6$ & $7.85+0.6$ & $5.1+1$ & $5.4+1.1$ \\
\hline $\mathrm{t}$ & \multicolumn{2}{|c|}{6.37} & \multicolumn{2}{|c|}{2.69} \\
\hline $\mathrm{P}$-value & \multicolumn{2}{|c|}{0.00001} & \multicolumn{2}{|c|}{0.021} \\
\hline
\end{tabular}

BX:- vertical distance between B point and Frankfort horizontal line $\mathrm{X}$

GoX:- vertical distance between Go and Frankfort horizontal line X

\section{Discussion:-}

The present study has presenteda new modality for TMJ arthroplasty.It was used to release long standing and recurrent bony ankylosis with extensive bony mass. It designed semi-sagittal osteotomy of the ankylosing bony mass to prevent shortening of ascending ramus, limiting the frequency ofdeveloping open bite and backward and upward position of the mandible. The present techniquewas planned also to avoid injury to the important vital structures located medial to the ankylosing bony mass. Creation of the conventional gap may endanger the common carotid artery at its entrance in the petrous part of temporal bone and the internal maxillary artery may also be jeopardized ${ }^{(17-20)}$.

The advantage of semi-sagittal splitting of the ankylosing bony mass is intended to transfer the false joint inferiorly to keep the posterior vertical height. The outer cut at the root of zygomatic arch isdirected medially and downward to emerge just above the mandibular foramen. Excessive functional rehabilitation movement tend to change the 
spongy interface of large area of bony cuts into cartilage producing false joint (Figure 8) with minimum compromise of the posterior vertical dimension. Bodily translation of the ramus downward by gravitation and release of pterygomasseteric sling will widen the osteotomy line and change it into semi-vertical gap. Creation of the gap on the expense of ankylosing bony mass may induce shortening of ramus with subsequentdecrease in posterior vertical heightand creation of postoperative anterior open bite.This opinion was supported by many authors. ${ }^{(21-25)}$ For this reason the current technique was introduced.

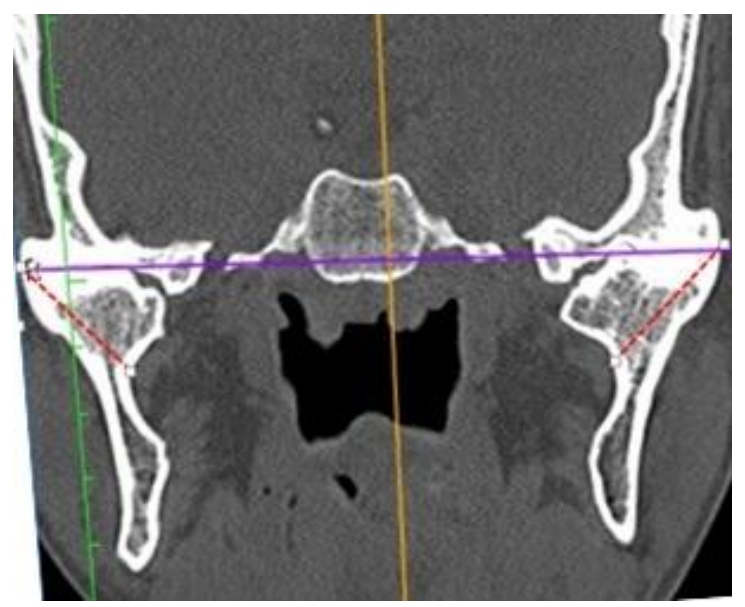

Figure 8:-Coronal cut represent how the semi sagittal split osteotomy preserve the posterior vertical height and the use of superior medial part of the ankylosing bony mass to protect the major and important vessels at the medial aspect of the mass.

The semi-sagittal split osteotomy is intended to preserve the ankylosing bony mass instead of its removal as stated by others. The present technique is designed to avoid cutting of bone medially (Figure 5\& 8) and desist entering of areas of disorderly bone deposition at the base of skull in close proximity to the carotid canal and middle meningeal artery (Figure 9). In order to prevent injury to vital structures medial to ankylosing bony mass the cutting was done with three methods; first the outer cortex was cut using surgical bur, the wide slot was created in cancellous bone by using gentle tapping on the different thickness of $6 \mathrm{~mm}$ widthosteotome,finally the medial cortex was splitted by the useof leverage by simple hand rotation of the inserted osteotome. The proposed technique is intended to keep away the sharp edge of the osteotome and blind rotating cutting surgical burs not to reach the medial cortex and the leverage usually induce tension at the medial cortex.



Figure 9:-Axial and coronal cuts showing petrous temporal thick and more radiodensity) 
Treatment of recurrent or long standing TMJ ankylosis with massive bony massby conventional gap arthroplasty poses a significant challenge because of technical difficulties, a high incidence of recurrence, and development of open bite. A variety of techniques for treatment have been described in the literature. However, no single method has achieved uniformly successful results. Previous study reported that the factors affecting the incidence of reankylosis are: disregard of post-operative physiotherapy, technique of surgery and inadequate intraoperative maximum interincisal opening (less than $35 \mathrm{~mm})^{(8,9,16.21,26.27)}$. In the present research three items are going to help translation of the ramus and released mandible inferiorly hence the semi-sagittal split osteotomy will be transformed into gap,these three items are: gravity, release of pterygomasseteric sling and muscle rehabilitation program.

The complications encountered in the present study as numbness of lower lip16.7\%; it represent only two cases; this is due to occupancy of the mandibular foramen a higher position in ankylosis patients than normal subjects as reported by Dehis et al ${ }^{(28)}$. The existence of weakening of the zygomatic and frontal branches of facial nerve $(25 \%)$ is attributed to heavy soft tissue retraction during surgery. The developed open bite was also so minimal( $8.3 \%)$ and this is because the case was long standing TMJ ankylosis in an old age female with subsequent deficiency in ramus height. The muscle was severely fibrosed with the resultant affection of neuromuscular transmission. Excessive consolidation of the cortical bone was the cause of fragmentation that seen in the osteotomy cut $(8.3 \%)$. Tendency for recurrence of TMJ ankylosis (8.3\%) was due to delinquency of the physiotherapy by the patients and disappearance during the critical first five weeks of follow up.

The present study concluded that, the semi-sagittal osteotomy is indicated in cases with excessive bulbous ankylosing bony mass that extend medially along the petrous temporal bone, this technique is recommended in order to preserve the major vital structures at the base of the skull and avoid further shortening of the ramus by bone loss due to creation of the horizontal gap in already deficient ramus height.

Recommendations:computer guided surgery for creation of template to guide this semi-sagittal osteotomy is recommended and represent the future field in the developing countries.

\section{References:-}

1. Braimah R, Taiwo A, Ibikunle A, Oladejo T, Adeyemi M, Adejobi F, Abubakar S:Clinical experience in managing temporomandibular joint ankylosis: five-year appraisal in a Nigerian subpopulation. J Korean Assoc Oral Maxillofac Surg. 2018 Jun;44(3):112-119. doi: 10.5125/jkaoms.2018.44.3.112. Epub 2018 Jun 26.

2. Dingman Ro, Grabb WC: Reconstruction of both mandibular condyles with metatarsal bone grafts. PlastReconstr Surg. 1964 Nov;34:441-51.

3. MacIntosh RB, Henny FA.: A spectrum of application of autogenouscostochondral grafts. J Maxillofac Surg. 1977 Nov;5(4):257-67.

4. Wolford LM, Cottrell DA, Henry C.: Sternoclavicular grafts for temporomandibular joint reconstruction. J Oral Maxillofac Surg. 1994 Feb;52 (2):119-28; discussion 128-9.

5. Potter JK, Dierks EJ.: Vascularized options for reconstruction of the mandibular condyle. SeminPlast Surg. 2008 Aug; 22(3):156-60. doi: 10.1055/s-2008-1081399.

6. Loveless TP, Bjornland T, Dodson TB, Keith DA: Efficacy of temporomandibular joint ankylosis surgical treatment. J Oral Maxillofac Surg. 2010 Jun; 68(6):1276-82. doi: 10.1016/j.joms.2009.10.014. Epub 2010 Mar 20.

7. Danda AK, S R, Chinnaswami R: Comparison of gap arthroplasty with and without a temporalis muscle flap for the treatment of ankylosis. J Oral Maxillofac Surg. 2009 Jul;67(7):1425-31. doi: 10.1016/j.joms.2008.12.049.

8. Beirne OR: Using the gap arthroplasty to treat temporomandibular joint ankylosis may result in temporomandibular joint ankylosis may result in greater mandibular range of motion than treating the ankylosis usingankylosisresection and Ramus-Condyle reconstruction with costochondral grafting. J Evid Based Dent Pract. 2012 Dec; 12(4):190-2. doi: 10.1016/j.jebdp.2012.09.008.

9. Kaban LB, Perrott DH, Fisher K: A protocol for management of temporomandibular joint ankylosis. J Oral Maxillofac Surg. 1990 Nov; 48(11):1145-51; discussion 1152.

10. Li J, Zhu S, Wang T, Luo E, Xiao L, Hu J.: Staged treatment of temporomandibular joint ankylosis with micrognathia using mandibular osteodistraction and advancement genioplasty. J Oral Maxillofac Surg. 2012 Dec; 70 (12):2884-92. doi: 10.1016/j.joms.2012.02.021. Epub 2012 May 16.

11. Vasconcelos BC, Bessa-Nogueira RV, Cypriano RV: Treatment of temporomandibular joint ankylosis by gap arthroplasty. Med Oral Patol Oral Cir Bucal. 2006 Jan 1; 11(1):E66-9. 
12. Yu H, Shen G, Zhang S, Wang X: Gap arthroplasty combined with distraction osteogenesis in the treatment of unilateralankylosis of the temporomandibular joint and micrognathia. Br J Oral Maxillofac Surg. 2009 Apr; 47(3):200-4. doi: 10.1016/j.bjoms.2008.08.003. Epub 2008 Sep 21.

13. Shoyeb K Shaikh, Madan Mishra, Arunesh Kumar Tiwari, Mahesh Chander, Amit Gaur, Harmurti Singh. Comparative evaluation of gap arthroplasty and interpositional arthroplasty using temporalis fascia in the management of temporomandibular joint ankylosis. J OrofacialResarch 20.13; 3:170-174.

14. Mohammad Ali Hossain, Syed Adnan Ali Shah, RajatSanker Roy Biswas: Frequency of Temporomandibular Joint Ankylosis in Various Age Groups with Reference to Etiology. ChattagramMaa-O-Shishu Hospital Medical College Journal. 13: 17-20; 2014.DOI: 10.3329/cmoshmcj.v13i2.21056

15. Yan Y, Zhang Y, Sun Z, Li J, Xiao E, An J: The relationshipbetween mouth opening and computerized tomographic features of posttraumatic bony ankylosis of the temporomandibular joint.Oral Surg Oral Med Oral Pathol Oral RadiolEndod. 2011 Mar; 111(3):354-61. doi: 10.1016/j.tripleo.2010.11.029.

16. Roychoudhury A, Parkash H, Trikha A: Functional restoration by gap arthroplasty in temporomandibular joint ankylosis: a report of 50 cases. Oral Surg Oral Med Oral Pathol Oral RadiolEndod. 1999 Feb;87(2):166-9.

17. Balcioglu HA, Kilic C, Varol A, Ozan H, Kocabiyik N, Yildirim M: A Morphometric Study of the Maxillary Artery and Lingula in Relation to Mandibular Ramus Osteotomies and TMJ Surgery. Eur J Dent. 2010 Apr; 4(2):166-70.

18. Alderazi YJ, Shastri D, Wessel J, Mathew M, Kass-Hout T, Aziz SR, Prestigiacomo CJ, Gandhi CD: Internal Maxillary Artery Preoperative Embolization Using n-Butyl Cyanoacrylate and Pushable Coils for Temporomandibular Joint Ankylosis Surgry.World Neurosurg. 2017 May; 101:254-258. doi: 10.1016/j.wneu.2017.01.086. Epub 2017 Jan 31.

19. Kieth DA. Complications of temporomandibular joint surgery. Oral MaxillofacSurgClin North Am. 2003 May; 15(2):187-94.

20. Hoffman D, Puig L: Complications of TMJ surgery. Oral MaxillofacSurgClin North Am. 2015 Feb; 27(1):10924. doi: 10.1016/j.coms.2014.09.008.

21. Wolford LM: Temporomandibular joint devices: treatment factors and outcomes. Oral Surg Oral Med Oral Pathol Oral RadiolEndod. 1997 Jan; 83(1):143-9.

22. Danda AK, S R, Chinnaswami R: Comparison of gap arthroplasty with and without a temporalis muscle flap for the treatment of ankylosis.J Oral Maxillofac Surg. 2009 Jul; 67(7):1425-31. doi: 10.1016/j.joms.2008.12.049.

23. Suneel Kumar Punjabi, Kashif Ali Channar, AmbreenMunir, and Qadeer-Ul-Hassan: A comparative study of gap \&interpositional arthroplasty with temporalis myofascial flap for TMJ ankylosis treatment. Pakistan Oral \& Dental Journal 33:426-429; 2013.

24. Movahed R, Mercuri LG: Management of temporomandibular joint ankylosis. Oral MaxillofacSurgClin North Am. 2015 Feb; 27(1):27-35. doi: 10.1016/j.coms.2014.09.003.

25. Sawhney CP: Bony ankylosis of the temporomandibular joint: follow-up of 70 patients treated with arthroplasty and acrylic spacer interposition. PlastReconstr Surg. 1986 Jan;77(1):29-40.

26. Erdem E, Alkan A: The use of acrylic marbles for interposition arthroplasty in the treatment of temporomandibular joint ankylosis: follow-up of 47 cases. Int J Oral Maxillofac Surg. 2001 Feb; 30(1):32-6.

27. Mercuri LG, Giobbie-Hurder A: Long-term outcomes after total alloplastic temporomandibular joint reconstruction following exposure to failed materials. Oral Maxillofac Surg. 2004 Sep;62(9):1088-96.

28. Dehis M, Tantawi W,Alnemer A: Effect of Temporomandibular Joint Bony Ankylosis on Location of the Mandibular Foramen. International Journal of Clinical oral and Maxillofacial Surgery. 2; 12-18:2016. 